\title{
Endorsement of Optimal ordering cycle implementing Quick Switching System with Single Sampling Plan with Permissible delay in Payments involving non-destructive testing
}

\author{
Aruna H M1, K. Pradeepa Veerakumari ${ }^{2^{*}}$, S. Suganya ${ }^{3}$ \\ ${ }^{1,2,3}$ Dep. of Statistics, Bharathiar University, Coimbatore, Tamil Nadu, India \\ "Corresponding Author: pradeepaveerakumari@bc.edu.in, Tel.: +919443937722
}

Available online at: www.isroset.org

Accepted 17/Aug/2018, Online 30/Aug/2018

\begin{abstract}
Quick Switching System-1 intensifies the likelihood of identifying the defects at the same time curtails the sample size. It consists of two intensity of inspection namely, normal and tightened inspection based on the number of defects. Tightened inspection with less acceptance number is employed when there is a possibility of high number of defects otherwise normal inspection is applied. Economic ordering quantity with permissible delay in payment enables the consumer optimal ordering size with the least possible cost and permissible late payment. Application of QSS-1 in EOQ model in permissible delay in payment has the benefits of cost-effective, reliable quality products. Case study on casting defects is given. Numerical illustrations are also provided to validate the results.
\end{abstract}

Keywords - Quick Switching System-1; Normal inspection; Tightened inspection; Economic Ordering Quantity; Permissible delay in payments.

\section{INTRODUCTION}

Acceptance Sampling is inevitably a protective system, originated as a defensive measure against the peril of the degeneration of the quality. When the sole purpose of the inspection is to either accept or reject the lot, based on the constancy of the standards acceptance sampling plan by attributes is employed. The main objective of the acceptance sampling plan is to curtail the inspection cost simultaneously assures the consumer that the consumer that satisfactory number of products are inspected. Acceptance sampling system refers to a collection of acceptance sampling plans or acceptance sampling scheme together with criteria by which appropriate plans or schemes may be chosen. Quick Switching System-1 is simple of all sampling schemes proposed by Romboski [1]. It consists of two sampling procedures with switching rules between normal and tightened inspection. Romboski has presented extensively a system of immediate switching to tightened inspection when the rejection comes under normal inspection and vice versa[1]. Due to rapid switching between normal and tightened plans, this system is referred as Quick Switching System-1(QSS-1). QSS-1 $\left(\mathrm{n}, \mathrm{c}_{\mathrm{N}}, \mathrm{c}_{\mathrm{T}}\right)$ consists of two sampling procedures $\left(\mathrm{n}, \mathrm{c}_{\mathrm{N}}\right) \&\left(\mathrm{n}, \mathrm{c}_{\mathrm{T}}\right)$ where $\mathrm{n}=$ sample size; $\mathrm{c}_{\mathrm{N}}=$ acceptance number under normal inspection;
$\mathrm{c}_{\mathrm{T}}=$ acceptance number under tightened inspection $\left(\mathrm{c}_{\mathrm{N}}<\mathrm{c}_{\mathrm{T}}\right)$. The probability of acceptance of Quick Switching System-1 is

$$
P_{a}=\frac{P_{T}}{\left(1-P_{N}\right)+P_{T}}
$$

Where,

$\mathrm{P}_{\mathrm{N}}=$ proportions of lots expected to be accepted using ( $\mathrm{n}$, $\mathrm{c}_{\mathrm{N}}$ ).

$\mathrm{P}_{\mathrm{T}}=$ proportions of lots expected to be accepted using $\left(\mathrm{n}, \mathrm{c}_{\mathrm{T}}\right)$. The modus operandi of QSS-1 is

1. At the outset, start using normal inspection with $\mathrm{c}_{\mathrm{N}}$.

2. If a lot is rejected $(\mathrm{d}>\mathrm{c})$, then switch to tightened inspection with $\mathrm{c}_{\mathrm{T}}$.

3. When on the tightened inspection, switch to normal inspection after a lot is accepted $(\mathrm{d}<\mathrm{c})$.

4. Alternate to and fro as imposed by the switching rules. The sample size $n, c_{N}, c_{T}$ are obtained from the table of Romboski.

The inspection is based on non-destructive testing. Tables are developed based on the QSS-1 with single sampling plan as reference plan under the conditions of Poisson distribution. It exactly deals with the defects per unit. The $\mathrm{np}$ value also known as unity value aids in construction and evaluation on 
the basis of the operating ratio idlest $\mathrm{p}_{2} / \mathrm{p}_{1}$. The sampling plan parameters are derived with the objective of satisfying both the producer risk $\alpha$ and consumer risk $\beta$. For the predetermined sampling strength $\left(\mathrm{p}_{1}, \alpha, \mathrm{p}_{2}, \beta\right)$ is the acceptance number and sample size is determined by applying the following procedure

- Calculate the operating ratio $\mathrm{R}=\mathrm{p}_{2} / \mathrm{p}_{1}$, where $\mathrm{p}_{1}=$ Acceptable Quality Level(AQL); $\mathrm{p}_{2}=$ Limiting Quality Level.

- Select a value of $\mathrm{R}$ from the table which is equal or just lesser than the desire value in terms of assuring both the risk.

- The acceptance number $\mathrm{c}$ can be obtained by using the closet value of the operating ratio

- The sample size $\mathrm{n}$ is obtained by calculating $n \mathrm{p}_{1} / \mathrm{p}_{1}$ or $\mathrm{np}_{2} / \mathrm{p}_{2}$, whichever is larger; always round off the sample size.

5. For instance, consider $\alpha=0.05 \& \quad \beta=0.10$, $\mathrm{p}_{1}=0.01 ; \mathrm{p}_{2}=0.04$; Then the operating ratio $\mathrm{R}=4$; $\mathrm{By}$ applying the table the value which is equal or just less than the desired value is 4.057 with $\mathrm{c}_{\mathrm{N}}=4 ; \mathrm{c}_{\mathrm{T}}=4$ and $\mathrm{np}_{1}=1.97 \& \mathrm{np}_{2}=7.994$. Then, the size of the sample $n=1.97 / 0.01=197$ or $7.994 / 0.04=199.85=200$.usually the larger sample size is selected. Therefore $n=200$. The values are extracted in Schilling as Table T17.1 .

The efficiency of the QSS-1 is it requires less acceptance number only when there is high number of defects. The result is that a succeeding lot is more likely to be rejected if proceeding lots have been rejected and more likely to be accepted if proceeding lots have been accepted. Application of the acceptance sampling by attributes has extended its core of its application. Tsao considered acceptance sampling plan in the EOQ model under the permissible delay in payments [3]. Pradeepa Veerakumari and Aruna developed economic ordering models under the conditions of permissible delay in payments with single sampling plan under the conditions of IPD with three payment privileges. Pradeepa Veerakumari and Aruna proposed an EOQ model with $\mathrm{c}=0$ single sampling plan with inspection errors. The present study incorporates Quick Switching System-1 with Economic Ordering Quantity with permissible delay in payments. The study is advantageous as it is cost-effective and less time consuming.

The study is organized as the section one consists of introduction, section 2 involves the model and formulation, Section 3 has optimal conditions, section 4 consists of the numerical illustrations and conclusion is provided at the end of the study.

\section{MODEL ASSUMPTIONS AND FORMULATION}

The assumptions made in the model are as follows
- QSS-1(n, $\left.\mathrm{c}_{\mathrm{N}}, \mathrm{c}_{\mathrm{T}}\right)$ with single sampling as reference plan is applied.

- Replenishment cycle time is instantaneous.

- $\quad$ Single product inventory is considered.

- Demand is known and invariable throughout the year.

- Lead time is zero

- $\mathrm{W}<\mathrm{S}, \mathrm{I}_{\mathrm{e}}<\mathrm{I}_{\mathrm{p}}$. Whereas, $\mathrm{W}$ is the price at which the product is sold to buyer and $\mathrm{S}$ is the price that sold back. $I_{e}$ is the Interest earned and $I_{p}$ is the interest paid.

Consider that the consumer places an order of size $\mathrm{Q}$ to the producer. It is assumed that the products in the rejected lots are sold at a reduced rate $\mathrm{G}$ per unit before the shipment of the next lot. The ordering cost is denoted as $\mathrm{C}_{\mathrm{o}}$ and the demand rate is $\mathrm{D}$. Then the modus operandi of the single sampling plan is applied. If the lot is accepted, the vendor offers the buyer, the permissible delay in the payments to owe the amount paid to the vendor. In practice, no interest is levied on the balance amount within the permissible delay in payments. But, if the payment is not paid after the closure of the permissible delay in payments, then interest is levied on the balance amount. Therefore leads to a valid point to the customer to delay the payments. On the contrast, permissible delay in payments attracts more new customers and already established customers will make more order to get the advantage of permissible delay in payments. So the permissible delay in payment is both favorable to the consumer and the producer. Total costs included in the model are the cost of placing orders $\mathrm{C}_{\mathrm{o}}$, inspection cost $\mathrm{C}_{\mathrm{i}}$, cost of holding the products $\mathrm{C}_{\mathrm{h}}$, cost of interest charges for unsold items, interest earned from the sales revenue. The model consists of two case, $\mathrm{T} \geq \mathrm{M}, \mathrm{T} \leq \mathrm{M}$ where $\mathrm{T}$ is the replenishment cycle time and $\mathrm{M}$ is the permissible delay payment period. The total cost function consists of the following costs

- Annual Ordering $\operatorname{Cost}=\frac{C_{o}}{T}$

- Annual Inspection $\cos t=\frac{C_{i} \cdot n}{T}$

- Annual cost for inventory holding $=\frac{\mathrm{DTC}_{\mathrm{h}}}{2}$

- Annual Interest earned involves two cases

Case 1

Suppose that $\mathrm{T} \geq \mathrm{M}$,

Annual Interest earned $=\frac{\text { S.I }_{\mathrm{e}} \mathrm{DM}^{2}}{2 \mathrm{~T}}$

Case 2:

Suppose that $\mathrm{T} \leq \mathrm{M}$, 
Annual Interest earned $=\frac{\mathrm{S}_{\mathrm{I}} \mathrm{DT}}{2}+\mathrm{S} \cdot \mathrm{I}_{\mathrm{e}} \cdot \mathrm{D}(\mathrm{M}-\mathrm{T})$

- Annual Interest Paid

Case 1

Suppose that $\mathrm{T} \geq \mathrm{M}$

Annual Interest paid $=\frac{\text { WD.I }}{\mathrm{p} \cdot(\mathrm{T}-\mathrm{M})^{2}}{ }^{2}$

Case 2

When $\mathrm{T} \leq \mathrm{M}$

Annual Interest charge $=0$. In this case, no interest charge is paid for the items.

Total cost, suppose that $T \geq M$

At first, if the lot is ordered, it is subjected to the inspection, if the lot is rejected, then the expected total cost,

$$
\mathrm{E}\left(\mathrm{TC}_{1}\right)=\frac{\mathrm{C}_{\mathrm{o}}}{\mathrm{T}}+\frac{\mathrm{C}_{\mathrm{i}} \cdot \mathrm{n}}{\mathrm{T}}-\mathrm{GD}
$$

The process is continued until the lot is accepted then, the total expected cost

$$
\begin{aligned}
& E\left(T C_{1}\right)= \\
& \left(\begin{array}{l}
\left(x+1\left(\frac{C_{o}}{T}+\frac{C_{i} \cdot n}{T}\right)\right)-x G D+ \\
P_{a} \sum_{x=0}^{\infty}\left(\begin{array}{l}
\frac{D T C_{h}}{2}+\frac{W \cdot D \cdot I_{p}(T-M)^{2}}{T}- \\
\frac{S . I_{e} D M^{2}}{2 T}
\end{array}\right)\left(1-P_{a}\right)^{x}
\end{array}\right)
\end{aligned}
$$

Then the series can be rewritten as,

\section{OPTIMAL CONDITIONS FOR THE OPTIMAL REPLENISHMENT CYCLE TIME}

Optimal value of $\mathrm{T}^{*}$ with minimum variable cost is obtained by using the concepts of maxima and minima in

$$
\begin{aligned}
& E\left(T C_{1}\right)= \\
& P_{a}\left(\begin{array}{l}
\left(\sum_{x=0}^{\infty}(x+1)\left(\frac{C_{o}}{T}+\frac{C_{i} \cdot n}{T}\right)\right)-\sum_{x=0}^{\infty}\left(1-P_{a}\right)^{x} x G D+ \\
\sum_{x=0}^{\infty}\left(1-P_{a}\right)^{x}\left(\begin{array}{l}
\frac{D T C_{h}}{2}+\frac{W . D . I_{p}(T-M)^{2}}{T}-I_{e} D M^{2} \\
2 T
\end{array}\right)
\end{array}\right)
\end{aligned}
$$

Then the infinite series expansion is

$$
\begin{aligned}
& \sum_{x=0}^{\infty}\left[(1+x)\left(1-P_{a}\right)^{x}\right]=\frac{1}{P_{a}^{2}} \\
& \sum_{x=0}^{\infty} x\left(1-P_{a}\right)^{x}=\frac{1-P_{a}}{P_{a}^{2}}
\end{aligned}
$$

$$
\sum_{\mathrm{x}=0}^{\infty}\left(1-\mathrm{P}_{\mathrm{a}}\right)^{\mathrm{x}}=\frac{1}{\mathrm{P}_{\mathrm{a}}}
$$

Substituting the values of 11 to 13 in eqn 10 , total expected cost function becomes,

$\left(T C_{1}\right)=$

$$
\left(\begin{array}{l}
\left(\frac{C_{o}}{T}+\frac{C_{i} \cdot n}{T}\right)-\left(1-P_{a}\right) G D \\
+P_{a}\left(\frac{D T C_{h}}{2}+\frac{W \cdot D \cdot I_{p}(T-M)^{2}}{T}-\frac{S . I_{e} D M^{2}}{2 T}\right)
\end{array}\right)
$$

Similarly, the total function, suppose that $T \leq M$, is

$\left(T C_{2}\right)=$

$$
\left.\left(\begin{array}{l}
\left(\frac{C_{o}}{T}+\frac{C_{i} \cdot n}{T}\right)-\left(1-P_{a}\right) G D \\
+P_{a}\left(\frac{D T C_{h}}{2}-\frac{S . I_{e} D T}{2}-S . I_{e} \cdot D(M-T)\right.
\end{array}\right)\right)
$$

differential calculus. Differentiate Total variable cost with respect to $\mathrm{T}$. Since for, the maximum or minimum value of total variable cost its first order derivative should be zero. By equating first order derivative of total cost to zero, the 
optimal replenishment order cycle time $\mathrm{T}^{*}$ is obtained. To ensure the global minimum of $\mathrm{T}^{*}$, verify that second order derivative of total cost with respect to $\mathrm{T}$ is positive for any finite value of $\mathrm{Q}>0$. The first order derivative of $\mathrm{TC}_{1}$ is

$\frac{d T C_{1}}{d T}=\frac{-2\left(C_{o}+C_{i} \cdot n\right)+P_{a}\left(\begin{array}{l}\left(D T^{2}\left(C_{h}+W . I_{p}\right)\right) \\ -D M^{2}\left(W . I_{p}-S . I_{e}\right.\end{array}\right)}{2 T^{2}}$

Second order derivative of $\mathrm{TC}_{1}$ is

$$
\frac{d^{2} T C_{1}}{d T^{2}}=\frac{2\left(C_{o}+C_{i} \cdot n\right)-P_{a}\left(D M^{2}\left(W . I_{p}-S . I_{e}\right)\right.}{T^{3}}
$$

The first order derivative of $\mathrm{TC}_{2}$ is

$$
\frac{\mathrm{dTC}_{2}}{\mathrm{dT}}=\frac{-2\left(\mathrm{C}_{\mathrm{o}}+\mathrm{C}_{\mathrm{i}} \cdot \mathrm{n}\right)+\mathrm{P}_{\mathrm{a}}\left(\mathrm { DT } ^ { 2 } \left(\mathrm{C}_{\mathrm{h}}+{\left.\left.\mathrm{S} . \mathrm{I}_{\mathrm{e}}\right)\right)}^{2}\right.\right.}{2 \mathrm{~T}^{2}}
$$

Second order derivative of $\mathrm{TC}_{2}$ is

$$
\frac{\mathrm{d}^{2} \mathrm{TC}_{2}}{\mathrm{dT}^{2}}=\frac{2\left(\mathrm{C}_{\mathrm{o}}+\mathrm{C}_{\mathrm{i}} \cdot \mathrm{n}\right)}{\mathrm{T}^{3}}
$$

From equation (18) that the $\mathrm{TC}_{1}$ is minimum only when, $2\left(C_{0}+C_{i} \cdot n\right)-P_{a}\left(D M^{2}\left(W . I_{p}-S . I_{e}\right)>0\right.$, equation(20) clearly indicates that the $\mathrm{TC}_{2}$ is global minimum. The optimal replenishment cycle time $\mathrm{T}_{1} *$ associated with the $\mathrm{TC}_{1}$ is

$$
\mathrm{T}_{1}^{*}=\sqrt{\frac{2\left(\mathrm{C}_{\mathrm{o}}+\mathrm{C}_{\mathrm{i}} \cdot \mathrm{n}\right)+\mathrm{P}_{\mathrm{a}} \cdot \mathrm{DM}^{2}\left(\mathrm{~W} \cdot \mathrm{I}_{\mathrm{p}}-\mathrm{S} \cdot \mathrm{I}_{\mathrm{e}}\right)}{\mathrm{D}\left(\mathrm{C}_{\mathrm{h}}+\mathrm{W} \cdot \mathrm{I}_{\mathrm{p}}\right) \cdot \mathrm{P}_{\mathrm{a}}}}
$$

Similarly, the optimal replenishment cycle time $\mathrm{T}_{2}{ }^{*}$ is obtained

$$
\mathrm{T}_{2}^{*}=\sqrt{\frac{2\left(\mathrm{C}_{\mathrm{o}}+\mathrm{C}_{\mathrm{i}} \cdot \mathrm{n}\right)}{\mathrm{D}\left(\mathrm{C}_{\mathrm{h}}+\mathrm{S}_{\mathrm{e}}\right) \cdot \mathrm{P}_{\mathrm{a}}}}
$$

The optimal condition for $\mathrm{T}>\mathrm{M}$ is obtained by equating the value of the $T_{1}{ }^{*}>M$ then by taking square roots on both sides.

$$
\mathrm{T}_{1}^{*}=\sqrt{\frac{2\left(\mathrm{C}_{\mathrm{o}}+\mathrm{C}_{\mathrm{i}} \cdot \mathrm{n}\right)+\mathrm{P}_{\mathrm{a}} \cdot \mathrm{DM}^{2}\left(\mathrm{~W} \cdot \mathrm{I}_{\mathrm{p}}-\mathrm{S} \cdot \mathrm{I}_{\mathrm{e}}\right)}{\mathrm{D}\left(\mathrm{C}_{\mathrm{h}}+\mathrm{W} \cdot \mathrm{I}_{\mathrm{p}}\right) \cdot \mathrm{P}_{\mathrm{a}}}}>\mathrm{M}
$$

$$
\Delta=2\left(\mathrm{C}_{\mathrm{o}}+\mathrm{C}_{\mathrm{i}} \cdot \mathrm{n}\right)-\mathrm{DM}^{2}\left(\mathrm{C}_{\mathrm{h}}+\mathrm{S} \cdot \mathrm{I}_{\mathrm{e}}\right) \mathrm{P}_{\mathrm{a}}>0
$$

By applying this methodology, the optimal condition for $\mathrm{T}<\mathrm{M}$.i.e. $\mathrm{T}_{2}{ }^{*}<\mathrm{M}$ is obtained as $\Delta<0$ and if $\mathrm{T}=\mathrm{M}$ i.e. $\mathrm{T}_{1}{ }^{*}=\mathrm{T}_{2}{ }^{*}$ is $\Delta=0$.

\section{NUMERICAL ILLUSTRATIONS}

Casting defect is the unacceptable flaw in the metal casting process. The casting defects are categorized into five types viz, gas porosity, shrinkage defects, mold material defects, pouring metal defaults and metallurgical defects. Casting defects can be negatively impact the bottom line of the foundry. Foundry manufacturing process includes preparation of moulds, molding, casting etc. The products are examined using visual inspection by the experts with the sensory enhancing equipment for instance, stethoscope, magnifiers, and tooth pick. Various types of defects may be found during the inspection on the final product for instance, acceptable defects, remediable defects and major defects. It is assumed that the products manufactured are with acceptable and remediable defects and if the lot is rejected it is sold at the discounted rate of $\$ 1$. The demand for the iron cast is 1000 . The price of the iron cast is $\$ 12$ and the consumer sold it at $\$ 13$. Then, $I_{e}=10 \%$ and $\mathrm{I}_{\mathrm{p}}=15 \% ; \mathrm{M}=0.2 ; \mathrm{C}_{0}=\$ 35 ; \mathrm{C}_{\mathrm{h}}=\$ 0.5$ per unit $; \mathrm{C}_{\mathrm{i}}=\$ 1$ per unit; $\mathrm{p}=0.01$; The sample size and the acceptance number are achieved as shown in the section 1 with $c=4 ; n=200$. The value of $\Delta=2\left(C_{0}+C_{i} \cdot n\right)-D^{2}\left(C_{h}+S \cdot I_{e}\right) P_{a}$ is 174 which is greater than zero. Then the optimal replenishment cycle interval time is $\mathrm{T}_{1}{ }^{*}=0.4613$ and the associated least possible cost is $\$ 662.60$.

\section{Conclusion}

Applying single sampling plan by attributes in visual inspection of welds helps to identify the defects with nondestructive testing of the products leads to minimized cost and less time consuming. QSS-1 carries the advantage of having two intensity of inspection; tightened inspection with 
less acceptance number is applied only when there is a possible of the high number of defects otherwise normal inspection is applied. As a consequence of the permissible delay in payments, the replenishment cycle interval \& ordering cost usually rise to some extent, but there is a considerable decrease in the total annual cost. Thus the study is cost-effective and less time. Future scope of the research includes the probability demand as the model considers deterministic demand. In the view of acceptance sampling, it may be extended to Skip-lot sampling plan of type 2, Quick Switching System-1 with destructive testing.

\section{REFERENCES}

[1]. Romboski L D. "An Investigation of Quick Switching Acceptance Sampling Systems" .Ph.D Thesis. RutgersThe State University New Brunswick. New Jersey, 1969.

[2].Schilling .E.G. "Acceptance Sampling in Quality Control". Marcel Dekker, New York, 1982.

[3]. Tsao.Y.C. "Optimal Ordering policy under Acceptance Sampling plan and trade credit financing", Transaction E: Industrial Engineering. 17(2) :120-128, 2010.

[4]. PradeepaVeerakumari.K, Aruna.H.M. "Application of $S S P$ for determination of influence over trade credit with payment choice", International Journal of pure and Applied Mathematics, 117(13),193-201, 2017.

[5].PradeepaVeerakumari.K, Aruna.H.M., "Determination of Economic Ordering Policies under Trade credit with Application of Zero Acceptance number Single Sampling by Attributes involving Destructive Testing, Inspection Errors", International Journal of Scientific Research in Mathematical and Statistical Sciences,5(3),79-84, 2018.

\section{AUTHORS PROFILE}

Ms. H.M. Aruna is now pursuing her $\mathrm{PhD}$ in the Department of Statistics, Bharathiar University, Coimbatore, Tamil Nadu, India. Her field of researches are Operations Research, Acceptance Sampling Plan and Reliability.

Ms. Dr. K. Pradeepa Veerakumari pursed M.Sc and Ph.D. Statistics from Bharathiar University, Coimbatore in 2004 \& 2009. She is currently working as Assistant Professor in Department of Statistics from Bharathiar University, Coimbatore since 2011. She is a Life member of ISPS and IISA since 2004. She has published more than 25 research papers in reputed National/International journals including Thomson Reuters (SCI/SCI-E, Scopes, Google Scholar and Web of Science) and it's also available online. Her main research work focuses on Statistical Quality Control, Neural Network, Bayesian Sampling, Operations Research and Experts Systems. She has 9 years of teaching experience and 14 years of research experience. She has produced 4 Doctorates.

Miss. S. Suganya is now pursuing her $\mathrm{PhD}$ in the Department of Statistics, Bharathiar University, Coimbatore, Tamil Nadu, India. Her field of research is Acceptance Sampling Plan, operations research, Numerical methods and Reliability.

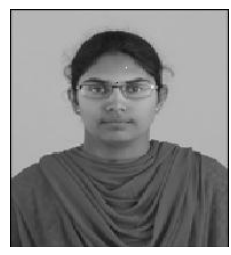

Note: Bharathiar University is an "A" grade University as per NAAC. Today, the University was ranked as $13^{\text {th }}$ position by india. 